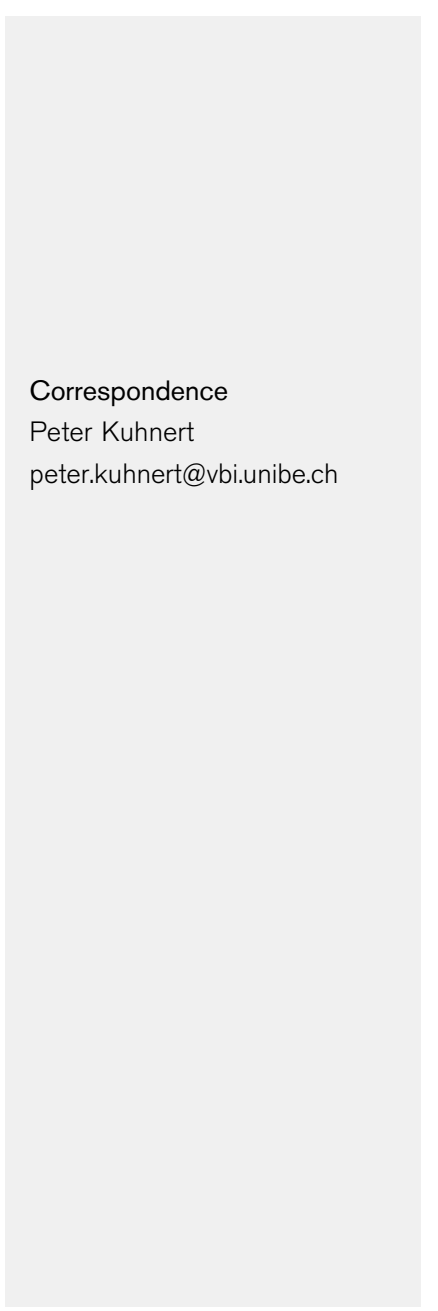

\title{
Basfia succiniciproducens gen. nov., sp. nov., a new member of the family Pasteurellaceae isolated from bovine rumen
}

\author{
Peter Kuhnert, ${ }^{1}$ Edzard Scholten, ${ }^{2}$ Stefan Haefner, ${ }^{2}$ Désirée Mayor ${ }^{1}$ \\ and Joachim Frey ${ }^{1}$ \\ ${ }^{1}$ Institute of Veterinary Bacteriology, Vetsuisse Faculty, University of Bern, Switzerland \\ ${ }^{2}$ BASF SE, Ludwigshafen, Germany
}

\begin{abstract}
Gram-negative, coccoid, non-motile bacteria that are catalase-, urease- and indole-negative, facultatively anaerobic and oxidase-positive were isolated from the bovine rumen using an improved selective medium for members of the Pasteurellaceae. All strains produced significant amounts of succinic acid under anaerobic conditions with glucose as substrate. Phenotypic characterization and multilocus sequence analysis (MLSA) using $16 \mathrm{~S}$ rRNA, rpoB, infB and recN genes were performed on seven independent isolates. All four genes showed high sequence similarity to their counterparts in the genome sequence of the patent strain MBEL55E, but less than $95 \% 16$ S rRNA gene sequence similarity to any other species of the Pasteurellaceae. Genetically these strains form a very homogeneous group in individual as well as combined phylogenetic trees, clearly separated from other genera of the family from which they can also be separated based on phenotypic markers. Genome relatedness as deduced from the recN gene showed high interspecies similarities, but again low similarity to any of the established genera of the family. No toxicity towards bovine, human or fish cells was observed and no RTX toxin genes were detected in members of the new taxon. Based on phylogenetic clustering in the MLSA analysis, the low genetic similarity to other genera and the phenotypic distinction, we suggest to classify these bovine rumen isolates as Basfia succiniciproducens gen. nov., sp. nov. The type strain is JF4016 ${ }^{\top}\left(=\right.$ DSM $22022^{\top}=$ CCUG $\left.57335^{\top}\right)$.
\end{abstract}

The family Pasteurellaceae currently contains 14 recognized genera and over 60 species with validly published names (Christensen \& Bisgaard, 2008; Gregersen et al., 2009). These bacteria are commonly isolated from a broad range of vertebrate species, where they belong to the normal flora of mucosal membranes, some also acting as opportunistic pathogens (Kuhnert \& Christensen, 2008). Species of the Pasteurellaceae found in the bovine rumen include Mannheimia ruminalis, Actinobacillus lignieresii, [Actinobacillus] succinogenes and 'Mannheimia succiniciproducens'. The latter two species were found to be efficient producers of succinic acid, as reflected by their names. Based on phylogenetic analyses using several genes, both species are suggested to be excluded from their respective genera (Korczak \& Kuhnert, 2008). Moreover, whereas the name

Abbreviation: MLSA, multilocus sequence analysis.

The GenBank/EMBL/DDBJ accession number for the $16 \mathrm{~S}$ rRNA gene sequence of strain JF4016 ${ }^{\top}$ is FJ463881.

Phylogenetic trees based on $16 \mathrm{~S}$ rRNA, rpoB, infB and recN gene sequences, along with details of strains and the GenBank/EMBL/DDBJ accession numbers for the gene sequences determined in this study are available with the online version of this paper.
[Actinobacillus] succinogenes was validly published by Guettler et al. (1999), 'Mannheimia succiniciproducens' has no standing in nomenclature (http://www.bacterio. cict.fr) and the only representative strain of this species, strain MBEL55E, is a patent strain and not publicly available (Lee et al., 2002). This species therefore still awaits proper description and taxonomic classification.

To investigate the presence of members of the Pasteurellaceae in the bovine rumen we used a selective medium and repeatedly isolated strains genetically resembling 'M. succiniciproducens'. For further clarification of the taxonomy of these organisms we applied a polyphasic approach. Strains were phenotypically characterized by standard tests and extended conventional tube assays (Christensen et al., 2007; Dousse et al., 2008). Furthermore, strains were tested on the Vitek2 (bioMérieux) to check for phenotypic variation using the broad panel of reactions available on that system. The genetic characterization included 16S rRNA gene sequencing of all isolates (Kuhnert et al., 2002). In addition, partial sequences of the two housekeeping genes $r p o B$ (encoding the $\beta$-subunit of RNA polymerase) and inf $B$ 
(coding for translation initiation factor 2), which previously proved useful for characterization of members of the Pasteurellaceae, were included in the phylogenetic analysis (Korczak et al., 2004; Mayor et al., 2006). The rpoB gene sequence has also proved generally useful for bacterial species and genus delineation (Adekambi et al., 2008). Finally, the $r e c N$ sequence (encoding a DNA repair protein) of the novel strains was determined for calculation of genome similarities to other representative species of the family, as well as for phylogenetic analysis (Kuhnert \& Korczak, 2006). Screening for RTX toxin genes and cytotoxicity assays were performed for risk assessment of the species. The newly isolated strains were proposed to represent a new genus and species, Basfia succiniciproducens gen. nov., sp. nov.

\section{Isolation of strains}

A modified selective medium based on that described by Jacobsen \& Nielsen (1995) proved highly efficient for the isolation of species of the Pasteurellaceae. Whereas on standard sheep blood-agar plates no species of the Pasteurellaceae could be isolated from rumen juice, 50\% of colonies were species of Pasteurellaceae on the selective medium. Besides Basfia succiniciproducens gen. nov., sp. nov., several previously unknown representatives of the family as well as Bibersteinia trehalosi were isolated. The modified Pasteurellaceae selective medium (PSM) contained per litre $25 \mathrm{~g}$ BHI (Difco) and $18 \mathrm{~g}$ Bacto agar (Difco), and was adjusted to $\mathrm{pH}$ 7.5-7.6. After autoclaving, the medium was cooled to $45{ }^{\circ} \mathrm{C}, 50 \mathrm{ml}$ sheep blood was added and the medium was further supplemented with $3.5 \mathrm{ml} \beta$-NAD (200 mg ml${ }^{-1}$; Sigma), $2 \mathrm{ml}$ bacitracin $\left(50 \mathrm{mg} \mathrm{ml}{ }^{-1}\right.$; Sigma), $1 \mathrm{ml}$ lincomycin $\left(1 \mathrm{mg} \mathrm{ml} \mathrm{m}^{-1}\right.$; Sigma), $1 \mathrm{ml}$ nystatin $\left(50 \mathrm{mg} \mathrm{ml}^{-1}\right.$; Sigma) and $1 \mathrm{ml}$ crystal violet $\left(1 \mathrm{mg} \mathrm{ml}^{-1}\right.$; Merck).

Bovine rumen juice was collected from freshly slaughtered animals or from live nursing cows providing rumen juice for therapy. The animals were of different breeds and originated from Germany or from Switzerland. A total of seven individual animals from different farms were probed and strains isolated. Rumen juice was diluted $1: 10$ with LB medium and $50 \mu \mathrm{l}$ was plated on PSM plates and incubated at $37{ }^{\circ} \mathrm{C}$ overnight under $5 \% \mathrm{CO}_{2}$ atmosphere. Single colonies were picked and subcultured on trypticase soy blood agar plates. Genetic identification of each single colony was performed using the $16 \mathrm{~S}$ rRNA gene sequence (Kuhnert et al., 2002). Strains showing highest similarity to the genomic sequence of patent strain MBEL55E were repeatedly isolated (Hong et al., 2004). This strain is not publicly available and could not therefore be included in our analyses, except for phylogenetic analyses based on its published genome sequence (Hong et al., 2004). Single strains were kept from six animals and eight strains were isolated from one animal, resulting in a total of 14 strains included in the study (Supplementary Table S1, available in IJSEM Online).

\section{Multilocus sequence analysis (MLSA)}

Phylogenetic analysis based on 16S rRNA gene sequence clustered strains proposed as Basfia succiniciproducens gen. nov., sp. nov. in the proximity of the genus Nicoletella (Supplementary Fig. S1). However, they formed a clearly separated cluster and showed only $95 \%$ similarity to the Nicoletella 16S rRNA gene sequence. Heterogeneity for the 16S rRNA genes within the species Basfia succiniciproducens is low, with $99 \%$ or higher sequence similarity. Phylogeny based on the housekeeping genes showed closest relation of Basfia succiniciproducens to the genus Aggregatibacter in all three trees (Supplementary Figs S2-S4), with sequence similarities of 84.2, 82.4 and 70.2\% for $r p o B$, infB and $r e c N$, respectively. Again, the species was shown to be genetically very homogeneous, with sequence similarity between strains of $>99.3($ rpoB $),>99.0 \quad$ (infB) and $>98.4 \%$ $(\operatorname{rec} N)$. The eight strains isolated from the same individual (JF4213-JF4220) had identical 16S rRNA and rpoB gene sequences, and the $\inf B$ gene sequences from the three strains analysed were identical (Supplementary Table S1).

A combined tree of all four genes resulted in the same clear monophyletic branch of Basfia succiniciproducens strains, nearest to Aggregatibacter actinomycetemcomitans (Fig. 1). On the other hand, the proposed genus Basfia was very distant from the genus Mannheimia, which was located on the opposite of the two observed main clusters (Fig. 1).

The use of $\operatorname{recN}$ gene sequence similarities proved very useful for prediction of genome similarities as an alternative to DNA-DNA hybridization within the family Pasteurellaceae (Kuhnert \& Korczak, 2006; Christensen et al., 2007; Kuhnert et al., 2007; Bisgaard et al., 2007). Based on these publications it can be deduced that species within genera have similarity values of 0.4 or higher, whereas similarity values between species of different genera are less than 0.4. Table 1 shows the similarity values calculated on the basis of $\operatorname{recN}$ gene sequence similarities between the type strain of Basfia succiniciproducens gen. nov., sp. nov. and the type species of the currently known genera of the Pasteurellaceae (Kuhnert \& Korczak, 2006). All values were clearly below 0.4 , with the highest observed value with Aggregatibacter actinomycetemcomitans (0.27). This was highly correlated with the phylogenetic analysis using four genes (Fig. 1), where Basfia succiniciproducens clustered in the vicinity of Aggregatibacter actinomycetemcomitans. Also, from this analysis it was obvious that Basfia succiniciproducens is not related to the genus Mannheimia since Mannheimia haemolytica showed one of the lowest similarity values (0.05) with Basfia succiniciproducens. The genetic similarity values calculated based on $\operatorname{recN}$ (Table 1) correlated well with the clustering observed in the combined tree based on four genes (Fig. 1). Genera of the cluster that includes Basfia succiniciproducens showed similarity values that were clearly above 0.1 , whereas genera of the other cluster had values below 0.1. The correlation of the MLSA with the data derived from the $r e c N$ gene confirmed this gene as a 


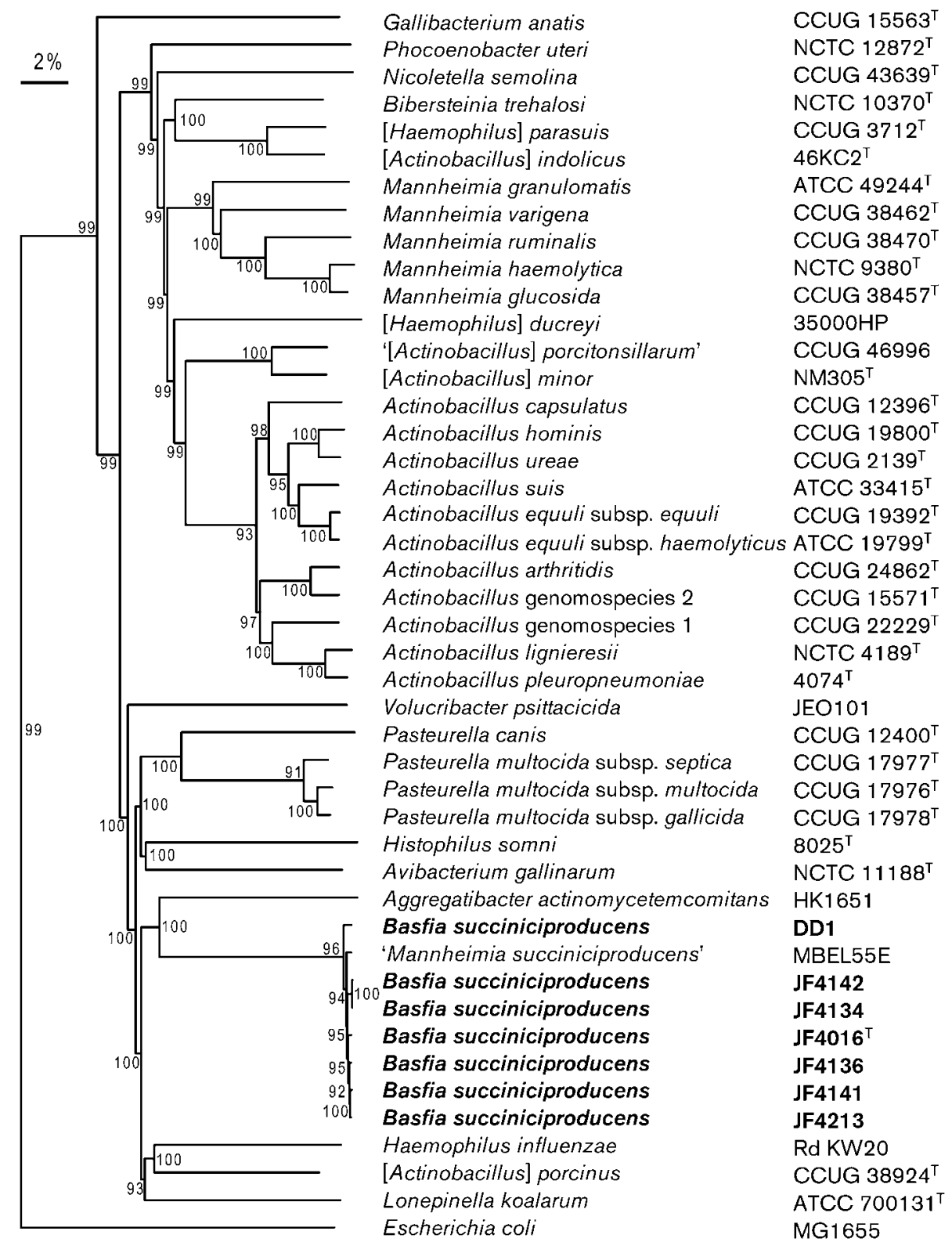

Fig. 1. Combined tree based on $16 \mathrm{~S}$ rRNA, rpoB, infB and recN gene sequences. Escherichia coli strain MG1655 was included as an outgroup to root the tree. The Jukes-Cantor correction was applied for the distance matrix and a neighbourjoining tree was reconstructed using Bionumerics v.5.1. Cophenic correlations are given, indicating the reliability of the branching compared with the actual genetic relatedness of the taxa. Bar, $2 \%$ sequence divergence. The accession numbers of the corresponding genes are given in the individual trees (Supplementary Figs S1-S4).

highly representative 'phylogene' for the Pasteurellaceae (Korczak \& Kuhnert, 2008). The similarity values within the species Basfia succiniciproducens were between 0.92 and 0.95 (data not shown), the latter being the value obtained with identical $\mathrm{recN}$ sequences. This low degree of variation again indicated the genetic homogeneity of the species. These similarity values are higher than those observed for variation within other species, for example Actinobacillus pleuropneumoniae (Kuhnert \& Korczak, 2006).

\section{Comparison of genome sequences of strains DD1 and MBEL55E}

The genome sequence of strain DD1, as a representative of the novel species, was determined by high-throughput sequencing (454; Life Science, Roche) with a 20 -fold coverage, and compared by BLAST to the sequence of strain MBEL55E (Altschul et al., 1997; Hong et al., 2004). Initial annotation was performed with Pedant-Pro 2.3-3.0 
Table 1. Genetic similarity of Basfia succiniciproducens gen. nov. sp. nov. to strains of type species of the Pasteure/laceae calculated based on $\operatorname{rec} N$ sequences

\begin{tabular}{|lc|}
\hline Species & $\begin{array}{c}\text { Similarity to Basfia } \\
\text { succiniciproducens }\end{array}$ \\
\hline Actinobacillus lignieresii NCTC $4189^{\mathrm{T}}$ & 0.04 \\
Pasteurella multocida CCUG $17976^{\mathrm{T}}$ & 0.18 \\
Haemophilus influenzae Rd KW20 & 0.25 \\
Mannheimia haemolytica NCTC $9380^{\mathrm{T}}$ & 0.05 \\
Lonepinella koalarum ATCC $700131^{\mathrm{T}}$ & 0.21 \\
Phocoenobacter uteri NCTC $12872^{\mathrm{T}}$ & 0.05 \\
Gallibacterium anatis CCUG $15563^{\mathrm{T}}$ & 0.02 \\
Volucribacter psittacicida JEO101 $^{\mathrm{T}}$ & 0.16 \\
Histophilus somni $8025^{\mathrm{T}}$ & 0.18 \\
Avibacterium gallinarum NCTC $11188^{\mathrm{T}}$ & 0.19 \\
Nicoletella semolina CCUG $43639^{\mathrm{T}}$ & 0.06 \\
Bibersteinia trehalosi NCTC $10370^{\mathrm{T}}$ & 0.06 \\
Aggregatibacter actinomycetemcomitans & 0.27 \\
HK1651 & \\
\hline
\end{tabular}

(Biomax Informatics). This software uses the Glimmer gene prediction algorithm for ORF finding (settings: allow ORFs extending off ends of sequence to be scored: true; minimum overlap length: 12; length of the smallest fragment considered to be a gene, in base pairs: 90). For tRNA annotation from within Pedant, tRNAscan-SE with default parameters was used. Both genomes were found to have a DNA G + C content of $42.5 \mathrm{~mol} \%$. The two strains had similar genome sizes of 2340000 bp for DD1 and
$2314078 \mathrm{bp}$ for MBEL55E, with 2363 and 2380 ORFs, respectively. Of these, 2006 ORFs were homologous between the two strains (core genome), whereas 145 putative genes present in strain DD1 showed no similarity to MBEL55E ORFs. The average similarity between the homologous proteins of both strains was $95 \%$ at the DNA as well as the amino acid sequence level.

\section{Phenotypic characterization}

Phenotypic and biochemical analysis was done by conventional tube tests, as recommended by the minimal standards for the description of genera, species and subspecies of the Pasteurellaceae (Christensen et al., 2007). Between two and eight phenotypic characters allowed separation of the genus Basfia gen. nov. from other genera within the Pasteurellaceae as listed in Table 2.

Further biochemical characterization was done on the Vitek2 system using GN and NH cards. Differences in acid production from some sugars were observed between the commercial Vitek2 system and the conventional tube assay. This has previously been seen with other commercial assays and may be due to the fact that they, as well as the Vitek2 test, use large inocula and short incubation times, thereby not necessarily measuring fermentation but rather acidification of sugars (Kuhnert et al., 2004).

Strains were tested for production of succinic acid using a UV-method-based kit according to the manufacturer (RBiopharm). All strains analysed produced similar levels of succinic acid under anaerobic conditions in liquid BHI

Table 2. Key characteristics for differentiation of Basfia succiniciproducens gen. nov. sp. nov. from other genera of the Pasteurellaceae

Genera: 1, Actinobacillus sensu stricto (Christensen \& Bisgaard, 2004); 2, Pasteurella sensu stricto (Mutters et al., 1985); 3, Haemophilus sensu stricto (includes $H$. influenzae, H. haemolyticus and H. aegyptius - results for H. parainfluenzae and H. pittmaniae are given in brackets; Nørskov-Lauritsen et al., 2005); 4, Mannheimia (Angen et al., 1999); 5, Lonepinella (Osawa et al., 1995); 6, Phocoenobacter (Foster et al., 2000); 7, Gallibacterium (Christensen et al., 2003); 8, Volucribacter (Christensen et al., 2004); 9, Histophilus (Angen et al., 2003); 10, Avibacterium (Blackall et al., 2005); 11, Nicoletella (Kuhnert et al., 2004); 12, Bibersteinia (Blackall et al., 2007); 13, Aggregatibacter (Patel et al., 2004; Nørskov-Lauritsen \& Kilian, 2006); 14, Basfia gen. nov. (this study). +, Positive; -, negative, v, variable; w, weakly positive; ND, no data available.

\begin{tabular}{|c|c|c|c|c|c|c|c|c|c|c|c|c|c|c|}
\hline Characteristic & 1 & 2 & 3 & 4 & 5 & 6 & 7 & 8 & 9 & 10 & 11 & 12 & 13 & 14 \\
\hline Catalase & $\mathrm{V}$ & $\mathrm{V}$ & $\mathrm{V}$ & $\mathrm{V}$ & - & - & + & $\mathrm{V}$ & - & $\mathrm{V}$ & + & $\mathrm{V}$ & $\mathrm{V}$ & - \\
\hline Urease & + & $--^{a_{\star}}$ & $+[\mathrm{v}]$ & - & - & - & - & - & - & - & + & - & - & - \\
\hline Indole & - & + & $\mathrm{V}$ & - & - & - & - & - & + & - & - & - & - & - \\
\hline Methyl red & - & - & $\mathrm{ND}$ & - & - & ND & $\mathrm{w}$ & + & $\mathrm{ND}$ & - & $\mathrm{ND}$ & - & - & + \\
\hline D-Galactose & $\mathrm{V}$ & + & + & + & $\mathrm{ND}$ & $\mathrm{ND}$ & + & + & $\mathrm{ND}$ & $\mathrm{v}$ & - & - & $\mathrm{v}$ & + \\
\hline D-Mannose & $\mathrm{V}$ & + & $-[+]$ & - & + & - & + & + & ND & + & - & + & $\mathrm{v}$ & + \\
\hline Sucrose & + & + & $-[\mathrm{v}]$ & + & $\mathrm{V}$ & - & + & + & - & + & - & + & $\mathrm{v}$ & + \\
\hline Trehalose & $\mathrm{V}$ & $\mathrm{V}$ & - & - & - & - & $\mathrm{v}$ & - & - & $\mathrm{V}$ & - & + & $\mathrm{V}$ & + \\
\hline D-Xylose & $+^{c}$ & $-{ }^{d}$ & $\mathrm{v}$ & + & $\mathrm{ND}$ & - & + & - & - & - & - & - & $\mathrm{v}$ & + \\
\hline$\alpha$-Glucosidase & $\mathrm{V}$ & + & - & - & - & ND & + & - & $\mathrm{ND}$ & + & $\mathrm{ND}$ & $\mathrm{V}$ & $\mathrm{v}$ & - \\
\hline
\end{tabular}


medium in a substrate dose-dependent manner. BHI alone without any additives resulted in about $0.5 \mathrm{~g}$ succinic acid $\mathrm{l}^{-1}$ after $19 \mathrm{~h}$ growth. If the standard concentration of $2 \mathrm{~g}$ glucose $1^{-1}$ in BHI was increased to $20 \mathrm{~g} \mathrm{l}^{-1}$, strains produced $>5 \mathrm{~g}$ succinic acid $\mathrm{l}^{-1}$. This was double the amount of succinic acid produced by Mannheimia glucosida or Escherichia coli strains included as controls. A more detailed biochemical study has previously been carried out with strain DD1 (Scholten \& Dagele, 2008).

\section{Toxicity assays}

Strain DD1, as a representative of the new species, was investigated for the presence of RTX toxin genes often found in the Pasteurellaceae (Frey \& Kuhnert, 2002) and for its toxicity towards various host cells in comparison to Mannheimia haemolytica, a bovine pathogen of the family Pasteurellaceae. A Southern-blot screening using broad-range gene probes for RTX toxins did not indicate the presence of known or related toxin genes (Kuhnert et al., 1997). This is in agreement with an in silico screening of the genome sequence of DD1, where no RTX toxins could be found using BLASTsearches at the DNA or amino acid levels. The same holds true for the genome sequence of strain MBEL55E (GenBank accession no. AE016827; Hong et al., 2004).

Toxicity was assayed with the bovine lymphoblastoid cell line BL20, the two human Burkitt lymphoma cell lines BJAP and Ramos, as well as the fish cell line EPC using the CytoTox 96 non-radioactive cytotoxicity assay (Promega). Cell lines were incubated for $4 \mathrm{~h}$ with either sterile bacterial culture supernatant or bacteria themselves. Mannheimia haemolytica strain SH1217 known to secrete the bovine hostspecific leukotoxin Lkt (Fedorova \& Highlander, 1997), as well as its culture supernatant, showed $20-30 \%$ cytotoxic activity towards bovine lymphoid cells but not towards human or fish cell lines. In contrast, Basfia succiniciproducens gen. nov., sp. nov. strain DD1 did not show any cytotoxicity towards bovine, human or fish cell lines.

\section{Description of Basfia gen. nov.}

Basfia (Bas.fi'a. N.L. fem. n. Basfia derived from the chemical company BASF SE in Ludwigshafen, Germany, in reference to the origin of the first strain characterized).

A member of the family Pasteurellaceae. Gram-stainnegative, non-motile cells. Do not require $\beta$-NAD or haemin for growth. Oxidase-positive. Negative reactions for catalase, urease, indole and $\alpha$-glucosidase. Positive for methyl red and negative for Voges-Proskauer reactions. In conventional tube assays, acid is produced from Dgalactose, D-mannitol, D-mannose, sucrose, trehalose and D-xylose. The type species is Basfia succiniciproducens.

\section{Description of Basfia succiniciproducens sp. nov.}

Basfia succiniciproducens (suc.ci.ni.ci.pro.du'cens. N.L. n. acidum succinicum succinic acid; L. part. adj. producens producing; N.L. part. adj. succiniciproducens succinic acid producing)

Grows on blood agar under facultatively anaerobic conditions at $37^{\circ} \mathrm{C}$. Capnophilic. Colonies are $0.1-$ $0.5 \mathrm{~mm}$ in diameter, shiny and greyish after $24 \mathrm{~h}$. Cells are coccoid to rod-shaped. Non-haemolytic. Produces succinic acid under anaerobic conditions in the presence of a substrate such as glucose. Glucose is fermented without production of gas. In conventional test tube assays, acid is produced from dextrin, maltose and D-fructose, whereas no acid is produced from adonitol, D-arabinose, cellobiose, dulcitol, myo-inositol, melezitose, D-sorbitol and D-salicin. Acid production from melibiose and Drhamnose is variable. On the Vitek2 GN and NH cards the following results are obtained. Positive reactions for $\alpha$ arabinosidase, $\beta$-galactosidase, leucine arylamidase, phenylalanine arylamidase, $N$-acetyl-D-glucosamine, $\beta$ galactopyranosidase, phosphorylcholine, D-mannitol, maltotriose, D-galactose, D-glucose, D-mannose, D-malate, Dribose, sucrose, trehalose, phosphatase and phenylphosphonate. Negative reactions for adonitol, L-arabitol, AlaPhe-Pro arylamidase, L-pyrrolidonyl arylamidase, tyrosine arylamidase, $\quad N$-acetyl- $\beta$-glucosaminidase, $\quad \gamma$-glutamyl transferase, glutamyl arylamidase, $\beta$-glucosidase, $\beta$-xylosidase, alanine arylamidase, L-proline arylamidase, lipase, palatinose, citrate, L-malate, urease, maltose, $\mathrm{H}_{2} \mathrm{~S}$, Dsorbitol, D-tagatose, D-xylose, malonate, L-lactate alkalinization, $\alpha$-glucosidase, starch (glycogen), succinate alkalinization, $N$-acetyl- $\beta$-galactosaminidase, glycine arylamidase, arginine arylamidase, ornithine decarboxylase, lysine decarboxylase, L-histidine, $\beta$-glucuronidase, GluGly-Arg arylamidase, L-lysine arylamidase, pyruvate and L-glutamine. Variable reactions were observed with cellobiose, 5 -keto-D-gluconate, $\alpha$-galactosidase, coumarate and Ellman's reagent. No toxicity towards lymphoid bovine and human cells or fish cells, and no RTX toxin genes observed. The DNA G $+\mathrm{C}$ content of the type strain is $42.5 \mathrm{~mol} \%$. Strains have been isolated from bovine rumen as part of the normal flora.

The type strain is $\mathrm{JF} 4016^{\mathrm{T}}\left(=\mathrm{DSM} 22022^{\mathrm{T}}=\mathrm{CCUG}\right.$ $57335^{\mathrm{T}}$ ) isolated from the rumen of a Simmental cow in Switzerland.

\section{Acknowledgements}

We thank Jacqueline Schmuckli, Barbara Müller and Antoinette Golomingi for preparing cell cultures and the slaughter unit of 'Metzgerei Holzer, Hindelbank' for providing rumen juice. The support of Andrea Hoerster for bioinformatic analyses is kindly acknowledged.

\section{References}

Adekambi, T., Shinnick, T. M., Raoult, D. \& Drancourt, M. (2008). Complete $r p o B$ gene sequencing as a suitable supplement to DNADNA hybridization for bacterial species and genus delineation. Int $J$ Syst Evol Microbiol 58, 1807-1814. 
Altschul, S. F., Madden, T. L., Schaffer, A. A., Zhang, J., Zhang, Z., Miller, W. \& Lipman, D. J. (1997). Gapped BLAST and PSI-BLAST: a new generation of protein database search programs. Nucleic Acids Res 25, 3389-3402.

Angen, Ø., Mutters, R., Caugant, D. A., Olsen, J. E. \& Bisgaard, M. (1999). Taxonomic relationships of the [Pasteurella] haemolytica complex as evaluated by DNA-DNA hybridizations and 16S rRNA sequencing with proposal of Mannheimia haemolytica gen. nov., comb. nov., Mannheimia granulomatis comb. nov., Mannheimia glucosida sp. nov., Mannheimia ruminalis sp. nov. and Mannheimia varigena sp. nov. Int J Syst Bacteriol 49, 67-86.

Angen, Ø., Ahrens, P., Kuhnert, P., Christensen, H. \& Mutters, R. (2003). Proposal of Histophilus somni gen. nov., sp. nov. for the three species incertae sedis 'Haemophilus somnus', 'Haemophilus agni' and 'Histophilus ovis'. Int J Syst Evol Microbiol 53, 1449-1456.

Bisgaard, M., Christensen, J. P., Bojesen, A. M. \& Christensen, H. (2007). Avibacterium endocarditidis sp. nov., isolated from valvular endocarditis in chickens. Int J Syst Evol Microbiol 57, 1729-1734.

Blackall, P. J., Christensen, H., Beckenham, T., Blackall, L. L. \& Bisgaard, M. (2005). Reclassification of Pasteurella gallinarum, [Haemophilus] paragallinarum, Pasteurella avium and Pasteurella volantium as Avibacterium gallinarum gen. nov., comb. nov., Avibacterium paragallinarum comb. nov., Avibacterium avium comb. nov. and Avibacterium volantium comb. nov. Int J Syst Evol Microbiol 55, 353-362.

Blackall, P. J., Bojesen, A. M., Christensen, H. \& Bisgaard, M. (2007). Reclassification of [Pasteurella] trehalosi as Bibersteinia trehalosi gen. nov., comb. nov. Int J Syst Evol Microbiol 57, 666-674.

Christensen, H. \& Bisgaard, M. (2004). Revised definition of Actinobacillus sensu stricto isolated from animals. A review with special emphasis on diagnosis. Vet Microbiol 99, 13-30.

Christensen, H. \& Bisgaard, M. (2008). Taxonomy and biodiversity of members of Pasteurellaceae. In Pasteurellaceae: Biology, Genomics and Molecular Aspects, pp. 1-26. Edited by P. Kuhnert \& H. Christensen. Norwich, UK: Caister Academic.

Christensen, H., Bisgaard, M., Bojesen, A. M., Mutters, R. \& Olsen, J. E. (2003). Genetic relationships among avian isolates classified as Pasteurella haemolytica, 'Actinobacillus salpingitidis' or Pasteurella anatis with proposal of Gallibacterium anatis gen. nov., comb. nov. and description of additional genomospecies within Gallibacterium gen. nov. Int J Syst Evol Microbiol 53, 275-287.

Christensen, H., Bisgaard, M., Aalbaek, B. \& Olsen, J. E. (2004). Reclassification of Bisgaard taxon 33 with proposal of Volucribacter psittacicida gen. nov., sp. nov. and Volucribacter amazonae sp. nov. as new members of Pasteurellaceae. Int J Syst Evol Microbiol 54, 813-818.

Christensen, H., Kuhnert, P., Busse, H. J., Frederiksen, W. C. \& Bisgaard, M. (2007). Proposed minimal standards for the description of genera, species and subspecies of the Pasteurellaceae. Int J Syst Evol Microbiol 57, 166-178.

Dousse, F., Thomann, A., Brodard, I., Korczak, B. M., Schlatter, Y., Kuhnert, P., Miserez, R. \& Frey, J. (2008). Routine phenotypic identification of bacterial species of the family Pasteurellaceae isolated from animals. J Vet Diagn Invest 20, 716-724.

Fedorova, N. D. \& Highlander, S. K. (1997). Generation of targeted nonpolar gene insertions and operon fusions in Pasteurella haemolytica and creation of a strain that produces and secretes inactive leukotoxin. Infect Immun 65, 2593-2598.

Foster, G., Ross, H. M., Malnick, H., Willems, A., Hutson, R. A., Reid, R. J. \& Collins, M. D. (2000). Phocoenobacter uteri gen. nov., sp. nov., a new member of the family Pasteurellaceae Pohl (1979) 1981 isolated from a harbour porpoise (Phocoena phocoena). Int $J$ Syst Evol Microbiol 50, 135-139.
Frey, J. \& Kuhnert, P. (2002). RTX toxins in Pasteurellaceae. Int J Med Microbiol 292, 149-158.

Gregersen, R. H., Neubauer, C., Christensen, H., Bojesen, A. M., Hess, M. \& Bisgaard, M. (2009). Comparative studies on [Pasteurella] testudinis and [Pasteurella] testudinis-like bacteria and proposal of Chelonobacter oris gen. nov., sp. nov. as a new member of the Pasteurellaceae. Int J Syst Evol Microbiol 59, 1583-1588.

Guettler, M. V., Rumler, D. \& Jain, M. K. (1999). Actinobacillus succinogenes sp. nov., a novel succinic-acid-producing strain from the bovine rumen. Int J Syst Bacteriol 49, 207-216.

Hong, S. H., Kim, J. S., Lee, S. Y., In, Y. H., Choi, S. S., Rih, J. K., Kim, C. H., Jeong, H., Hur, C. G. \& Kim, J. J. (2004). The genome sequence of the capnophilic rumen bacterium Mannheimia succiniciproducens. Nat Biotechnol 22, 1275-1281.

Jacobsen, M. J. \& Nielsen, J. P. (1995). Development and evaluation of a selective and indicative medium for isolation of Actinobacillus pleuropneumoniae from tonsils. Vet Microbiol 47, 191-197.

Korczak, B. M. \& Kuhnert, P. (2008). Phylogeny of Pasteurellaceae. In Pasteurellaceae: Biology, Genomics and Molecular Aspects, pp. 27-52. Edited by P. Kuhnert \& H. Christensen. Norwich, UK: Caister Academic

Korczak, B., Christensen, H., Emler, S., Frey, J. \& Kuhnert, P. (2004). Phylogeny of the family Pasteurellaceae based on rpoB sequences. Int $J$ Syst Evol Microbiol 54, 1393-1399.

Kuhnert, P. \& Christensen, H. (editors) (2008). Pasteurellaceae: Biology, Genomics and Molecular Aspects. Norwich, UK: Caister Academic.

Kuhnert, P. \& Korczak, B. M. (2006). Prediction of whole-genome DNA-DNA similarity, determination of $\mathrm{G}+\mathrm{C}$ content and phylogenetic analysis within the family Pasteurellaceae by multilocus sequence analysis (MLSA). Microbiology 152, 2537-2548.

Kuhnert, P., Heyberger-Meyer, B., Burnens, A. P., Nicolet, J. \& Frey, J. (1997). Detection of RTX toxin genes in Gram-negative bacteria with a set of specific probes. Appl Environ Microbiol 63, 2258-2265.

Kuhnert, P., Frey, J., Lang, N. P. \& Mayfield, L. (2002). A phylogenetic analysis of Prevotella nigrescens, Prevotella intermedia and Porphyromonas gingivalis field strains reveals a clear species clustering. Int J Syst Evol Microbiol 52, 1391-1395.

Kuhnert, P., Korczak, B., Falsen, E., Straub, R., Hoops, A., Boerlin, P., Frey, J. \& Mutters, R. (2004). Nicoletella semolina gen. nov., sp. nov., a new member of Pasteurellaceae isolated from horses with airway disease. J Clin Microbiol 42, 5542-5548.

Kuhnert, P., Korczak, B. M., Christensen, H. \& Bisgaard, M. (2007). Emended description of Actinobacillus capsulatus Arseculeratne 1962, $38^{\mathrm{AL}}$. Int J Syst Evol Microbiol 57, 625-632.

Lee, P. C., Lee, S. Y., Hong, S. H. \& Chang, H. N. (2002). Isolation and characterization of a new succinic acid-producing bacterium, Mannheimia succiniciproducens MBEL55E, from bovine rumen. Appl Microbiol Biotechnol 58, 663-668.

Mayor, D., Korczak, B. M., Christensen, H., Bisgaard, M., Frey, J. \& Kuhnert, P. (2006). Distribution of RTX toxin genes in strains of [Actinobacillus] rossii and [Pasteurella] mairii. Vet Microbiol 116, 194-201.

Mutters, R., Ihm, P., Pohl, S., Frederiksen, W. \& Mannheim, W. (1985). Reclassification of the genus Pasteurella Trevisan 1887 on the basis of deoxyribonucleic acid homology, with proposals for the new species Pasteurella dagmatis, Pasteurella canis, Pasteurella stomatis, Pasteurella anatis, and Pasteurella langaa. Int J Syst Bacteriol 35, 309-322.

Nørskov-Lauritsen, N. \& Kilian, M. (2006). Reclassification of Actinobacillus actinomycetemcomitans, Haemophilus aphrophilus, Haemophilus paraphrophilus and Haemophilus segnis as Aggrega- 
tibacter actinomycetemcomitans gen. nov., comb. nov., Aggregatibacter aphrophilus comb. nov. and Aggregatibacter segnis comb. nov., and emended description of Aggregatibacter aphrophilus to include V factor-dependent and V factor-independent isolates. Int J Syst Evol Microbiol 56, 2135-2146.

Nørskov-Lauritsen, N., Bruun, B. \& Kilian, M. (2005). Multilocus sequence phylogenetic study of the genus Haemophilus with description of Haemophilus pittmaniae sp. nov. Int J Syst Evol Microbiol 55, 449-456.
Osawa, R., Rainey, F. A., Fujisawa, T., Lang, E., Busse, H. J., Walsh, T. \& Stackebrandt, E. (1995). Lonepinella koalarum gen. nov., sp. nov., a new tannin-protein complex degrading bacterium. Syst Appl Microbiol 18, 368-373.

Patel, S. M., Mo, J. H., Walker, M. T., Adley, B. \& Noskin, G. A. (2004). Epidural abscess and osteomyelitis due to Actinobacillus actinomycetemcomitans. Diagn Microbiol Infect Dis 50, 283-285.

Scholten, E. \& Dägele, D. (2008). Succinic acid production by a newly isolated bacterium. Biotechnol Lett 30, 2143-2146. 